ARTICLE

\title{
Ocean acidification increases the accumulation of toxic phenolic compounds across trophic levels
}

\author{
Peng Jin ${ }^{1, \dagger}$, Tifeng Wang ${ }^{1}$, Nana Liu ${ }^{1}$, Sam Dupont ${ }^{2}$, John Beardall ${ }^{3}$, Philip W. Boyd ${ }^{4}$, \\ Ulf Riebesell ${ }^{5} \&$ Kunshan Gao ${ }^{1}$
}

Increasing atmospheric $\mathrm{CO}_{2}$ concentrations are causing ocean acidification (OA), altering carbonate chemistry with consequences for marine organisms. Here we show that $O A$ increases by $46-212 \%$ the production of phenolic compounds in phytoplankton grown under the elevated $\mathrm{CO}_{2}$ concentrations projected for the end of this century, compared with the ambient $\mathrm{CO}_{2}$ level. At the same time, mitochondrial respiration rate is enhanced under elevated $\mathrm{CO}_{2}$ concentrations by $130-160 \%$ in a single species or mixed phytoplankton assemblage. When fed with phytoplankton cells grown under OA, zooplankton assemblages have significantly higher phenolic compound content, by about $28-48 \%$. The functional consequences of the increased accumulation of toxic phenolic compounds in primary and secondary producers have the potential to have profound consequences for marine ecosystem and seafood quality, with the possibility that fishery industries could be influenced as a result of progressive ocean changes.

\footnotetext{
${ }^{1}$ State Key Laboratory of Marine Environmental Science, Xiamen University, Xiamen 361005, China. ${ }^{2}$ Department of Biological and Environmental Sciences, University of Gothenburg, 566 Kristineberg, Fiskebäckskil 45178, Sweden. ${ }^{3}$ School of Biological Sciences, Monash University, Clayton, Victoria 3800, Australia. ${ }^{4}$ Institute for Marine and Antarctic Studies and Antarctic Climate \& Ecosystems Cooperative Research Centre, University of Tasmania, Hobart, Tasmania 7005, Australia. ${ }^{5}$ GEOMAR Helmholtz Centre for Ocean Research Kiel, Düsternbrooker Weg 20,24105 Kiel, Germany. $†$ Present address: Red Sea Research Center, Division of Biological and Environmental Science and Engineering, King Abdullah University of Science and Technology,

Thuwal 23955-6900, Saudi Arabia. Correspondence and requests for materials should be addressed to K.G. (email: ksgao@xmu.edu.cn).
} 
ncreasing atmospheric $\mathrm{CO}_{2}$ levels are continuing to cause global warming, with increasing oceanic $\mathrm{CO}_{2}$ uptake playing an important role in the mediation of the extent of this increase. However, the rapid $\mathrm{CO}_{2}$ dissolution into seawater is also causing ocean acidification (OA), which progressively alters marine chemical environments, with consequences for many organisms. While physiological and ecological effects of ocean climate change on primary producers have been examined broadly ${ }^{1,2}$, little is known about the molecular aspects and/or metabolic pathways underlying the responses of phytoplankton to $\mathrm{OA}^{3}$. Moreover, there are growing concerns about the need to couple the data obtained from monospecific laboratory studies with that from natural communities, as well as under multiple stressor conditions ${ }^{4}$. In addition, the consequences of $\mathrm{OA}$ for energy transfer, food quality and the food web remain poorly understood.

To address this issue, we here employ a proteomics approach to investigate the responses of a coccolithophorid, Emiliania huxleyi (CCMP 1516) to elevated $\mathrm{CO}_{2}$ at the molecular level. On the basis of the findings of the proteomics study, we hypothesize that OA could enhance some metabolic pathways, leading to enhanced production of phenolic compounds. To test this, we measured the levels of phenolic compounds and mitochondrial respiration rates in phytoplankton in monospecific laboratory cultures and in mixed phytoplankton assemblages, grown under different levels of $\mathrm{CO}_{2}$. Subsequently, zooplankton assemblages were fed with phytoplankton cells grown under the elevated $\mathrm{CO}_{2}$ concentration to examine possible food chain effects. Our results show that OA increases the levels of phenolic compounds in phytoplankton by enhancing $\beta$-oxidation, Krebs cycle and mitochondrial respiration, and the accumulated phenolic compounds are transferred to higher trophic levels (zooplankton).

\section{Results}

Proteomic responses of phytoplankton to OA. When the coccolithophore, E. huxleyi (CCMP 1516), was grown monospecifically under low (LC, $395 \mu \mathrm{atm}) \mathrm{pCO}_{2}$ or, high ( $\mathrm{HC}, 1,000 \mu \mathrm{atm}) \mathrm{pCO}_{2}$, contrasting differences were found in the proteomics (Supplementary Fig. 1). The enzymes methane/ phenol/toluene hydroxylase, which plays key roles in phenolic compound biodegradation, propionyl CoA synthase and enoyl $\mathrm{CoA}$ hydratase that function in $\beta$-oxidation, adenylate kinase (ADK), which is a key enzyme in energy metabolism, and chloroplastic GADPH, were all upregulated in the HC-grown cells (Supplementary Table 1). However, another key enzyme in energy metabolism, nucleoside diphosphate kinase, transferring phosphoryl groups between the adenine and guanine pools $(\mathrm{GDP}+\mathrm{ATP} \text { to GTP }+\mathrm{ADP})^{5}$, was downregulated by about $50 \%$ in the HC-grown cells compared with the LC-grown cells (Supplementary Table 1), suggesting that relative ATP loss in cells under HC was slowed down. On the basis of these differentially expressed proteins and their functions, we hypothesized that elevated $\mathrm{CO}_{2}$ enhanced the metabolic pathway, described below, leading to enhanced production of phenolic compounds and their metabolism (Fig. 1).

The high $\mathrm{CO}_{2}$-induced changes in seawater carbonate chemistry might enhance the cellular production of phenolic compounds, but may also accelerate their biodegradation. As a consequence, enzymes such as phenol hydroxylase would be required for their biodegradation. The resulting products, cis, cis, muconic acid or 2-hydroxymuconic semialdehyde, are further metabolized via $\beta$-oxidation and, subsequently, expression of propionyl CoA synthase and enoyl CoA hydratase would be enhanced. The resulting product, acetyl $\mathrm{CoA}$, is a key precursor compound for the Krebs cycle, which functions in oxidizing

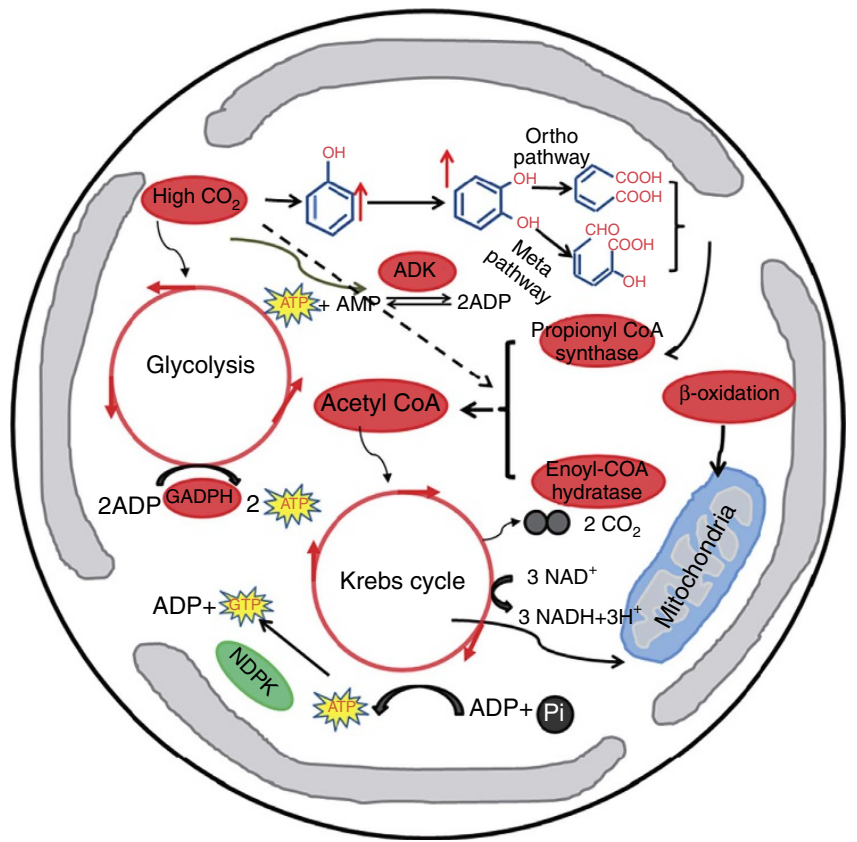

Figure 1 | Altered metabolic pathways under ocean acidification.

Metabolic pathways in the coccolithophorid Emiliania huxleyi altered under ocean acidification ( $\mathrm{HC}, \mathrm{CO}_{2} 1,000 \mu \mathrm{atm} ; \mathrm{pH}_{\mathrm{NBS}}$ 7.81) based on proteomic, physiological and biochemical analyses. More phenolic compounds were biosynthesized, subsequently biodegraded and then metabolized via $\beta$ oxidation and Krebs cycle, generating more ATP in the HC-grown cells by mitochondrial respiration. This extra energy can be used to counter the effects of high $\mathrm{CO}_{2}$ /low pH stress from the environment. Adenylate kinase (ADK) was upregulated, and glycolysis was accelerated in the HC-grown cells. On the other hand, nucleoside diphosphate kinase (NDPK) was downregulated, reflecting the slower loss of ATP loss in the HC-grown cells. The novel pathway including $\beta$-oxidation and the Krebs cycle becomes enhanced under ocean acidification to meet the extra energy requirement for maintaining homoeostasis. The red and green symbols represent upand downregulated proteins or processes, respectively.

acetyl CoA to $\mathrm{CO}_{2}$ and drives the synthesis of ATP. In such circumstances, the generation of ATP could thus be stimulated in the HC-grown cells (Fig. 1, Supplementary Table 1). Moreover, the enzyme chloroplast GADPH associated with glycolysis was upregulated in the HC-grown cells, indicating that energy demand under the elevated $\mathrm{CO}_{2}$ level was higher to operate cellular essential metabolism (Fig. 1, Supplementary Table 1). Together with this, ADK, a key enzyme in energy metabolism, catalysing a reversible transphosphorylation reaction interconverting ADP to ATP and AMP showed significantly higher expression in the HC-grown cells (Fig. 1, Supplementary Table 1). Hence, at least two lines of evidence have to be provided to support the above hypothesis: namely, a higher phenolic compound content and increased mitochondrial respiration rates in E. huxleyi grown under high $\mathrm{CO}_{2}$ conditions.

Biochemical and physiological tests. To test the above hypothesis, we measured the content of phenolic compounds and mitochondrial respiration rates in E. huxleyi cells grown under $\mathrm{HC}$ and LC conditions. The phenolic compounds were about $56 \%$ higher in the HC-acclimated cells than in the LC-acclimated cells (20 generations; analysis of variance (ANOVA) $1, \mathrm{~F}_{1,3}=119.53$, $P<0.001$ ) (Fig. 2a, statistical details in Supplementary Table 2). When the LC-acclimated cells were transferred to HC conditions, the phenolic compound content significantly increased by $24 \%$ 
a

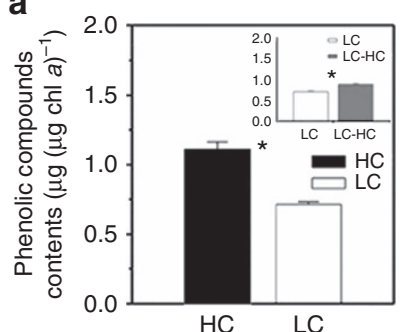

b

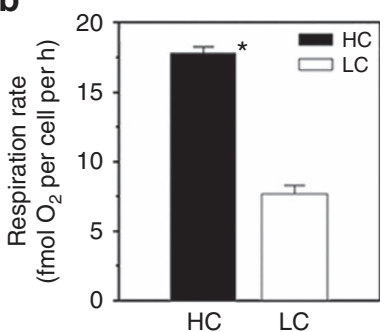

C

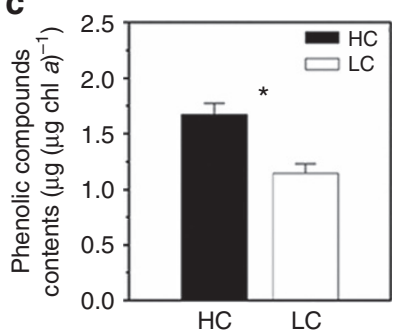

d
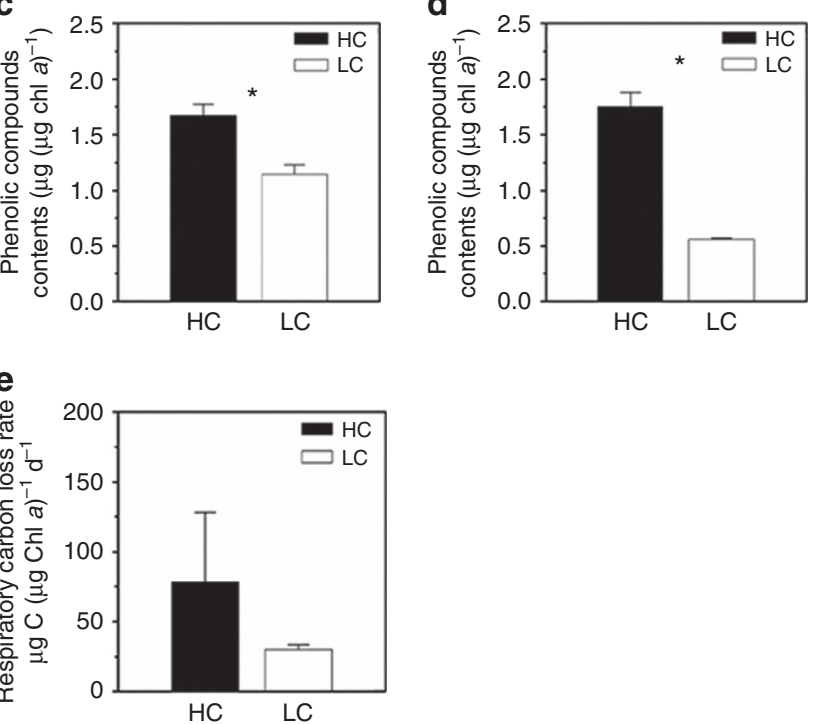
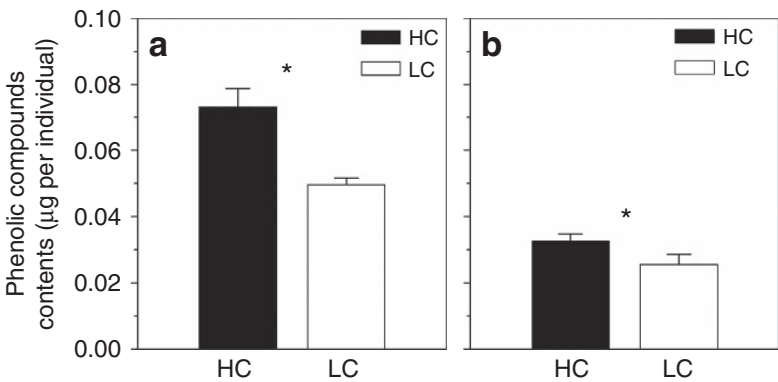

Figure 3 | Phenolic compounds contents in zooplankton. Content of phenolic compounds ( $\mu$ g per individual) in zooplankton assemblages (body size $>112 \mu \mathrm{m})$ that were fed on high $\mathrm{CO}_{2}\left(\mathrm{HC}, 1,000 \mu \mathrm{atm}, \mathrm{pH}_{\mathrm{NBS}} 7.81\right)$ or low $\mathrm{pCO}_{2}$ grown (LC, $395 \mu \mathrm{atm}, \mathrm{pH}_{\mathrm{NBS}}$ 8.16) phytoplankton cells collected from the microcosms (a, triplicate) or mesocosms (b, triplicate). The feeding tests were carried out in in situ seawater pre-equilibrated with the high $(1,000 \mu \mathrm{atm})$ or low $\mathrm{pCO}_{2}(395 \mu \mathrm{atm})$ levels, that is, $\mathrm{HC}$-grown zooplankton fed with $\mathrm{HC}$-grown phytoplankton (black column) or LC-grown zooplankton fed with LC-grown phytoplankton (white column). Details of statistics are shown in Supplementary Table 2. Vertical lines represent the s.d. of the means. ${ }^{*}$ indicates significance at the $P<0.05$ level.

(Fig. 2c, statistical details in Supplementary Table 2). During a mesocosm experiment (4,000 L; details in Supplementary Note 2) using The Facility for Ocean Acidification Impacts Study of Xiamen University $\left(24.52^{\circ} \mathrm{N}, 117.18^{\circ} \mathrm{N}\right.$, Wuyuan Bay, Xiamen, China, http://mel.xmu.edu.cn/facility.asp?id=33), the phytoplankton assemblages (dominated mainly by diatoms and coccolithophores) also showed elevated, by about $212 \%$, contents of phenolic compounds under high (HC, 1,000 $\mu \mathrm{atm}) \quad \mathrm{pCO}_{2}$ (ANOVA 2, model: $\mathrm{F}_{5,12}=10.91, P<0.001 ; \mathrm{CO}_{2}: \mathrm{F}_{1,12}=54.48$, $P<0.001$; Fig. 2d, statistical details in Supplementary Table 2), compared with that of the low $\mathrm{pCO}_{2}$ assemblages. Although the mean values of mitochondrial respiration were higher by $160 \%$ in the high $\mathrm{CO}_{2}$ mesocosms than in the low $\mathrm{CO}_{2}$ treatments, the difference was not significant due to a large variation in the data (ANOVA $1, \mathrm{~F}_{1,3}=2.78, P=0.171$; Fig. 2e, statistical details in Supplementary Table 2).

Transfer of phenolics to higher trophic level. Since biochemical compositions altered by $\mathrm{OA}$ in phytoplankton may have profound impacts on trophic energy transfer ${ }^{6,7}$, we therefore tested whether zooplankton fed with phytoplankton containing higher levels of phenolic compounds would also have higher concentrations of these toxic compounds in their bodies. When the zooplankton (dominated by calanoid copepods (95\%), of which Acartia pacifica accounted for up to $\sim 60 \%$, Supplementary Fig. 2) was fed with HC- and LC-grown phytoplankton cells under the high $(1,000 \mu \mathrm{atm})$ and low $(395 \mu \mathrm{atm}) \quad \mathrm{pCO}_{2}$ levels, higher contents of phenolic compounds were detected in their bodies at elevated $\mathrm{pCO}_{2}$, which was true either in the microcosms (47.5\%, ANOVA 2, model: $\quad \mathrm{F}_{5,6}=7.19, \quad P=0.016 ; \quad \mathrm{CO}_{2}: \quad \mathrm{F}_{1,6}=33.24, \quad P=0.001$; Fig. 3a) or when fed with phytoplankton cells from the mesocosms (27.8\%, ANOVA 2, model: $\mathrm{F}_{5,6}=8.15, P=0.012$; $\mathrm{CO}_{2}: \mathrm{F}_{1,6}=29.46, \quad P=0.002$; Fig. $3 \mathrm{~b}$, statistic details in Supplementary Table 2).

\section{Discussion}

On the basis of the outcomes of proteomics in the monospecific study with E. huxleyi and the physiological results from the monospecific study, microcosm and mesocosm tests with mixed phytoplankton species or natural phytoplankton assemblages, the 
present work suggests that a novel phenolic compound metabolism pathway, involving $\beta$-oxidation and the Krebs cycle, was enhanced by OA. While there are controversial findings on the effects of $\mathrm{OA}$ on mitochondrial respiration ${ }^{8-10}$, rising $\mathrm{pCO}_{2}$ and decreasing $\mathrm{pH}$ in seawater perturb the cytoplasmic acid-base balance of phytoplankton ${ }^{11}$, so that extra energy would be required to maintain the cell's homoeostasis or positive $\mathrm{H}^{+}$ efflux ${ }^{12}$. Enhanced photorespiratory carbon loss in high $\mathrm{CO}_{2}$ grown cells ${ }^{9,13}$ consumes additional energy for photoprotection. Consequently, an extra energy requirement for maintaining homoeostasis when phytoplankton cells are perturbed by changed seawater chemistry can be expected. In this study, we demonstrated that $\beta$-oxidation and the Krebs cycle were enhanced under $\mathrm{OA}$ and could thus meet any extra energetic demand to allow phytoplankton to tolerate acidic stress. For coccolithophores, increased phenolic compounds may not only reflect a way to endure with any extra energetic demand under OA but may also act as repellents to protect them from grazers as the cells calcify less under $\mathrm{OA}^{1}$.

It is a well-known phenomenon in higher plants that they increase the production of phenolic compounds to deter grazers. Our finding that phytoplankton increased the production of these compounds under high $\mathrm{CO}_{2}$ thus has implications for grazers, though the mechanism by which phytoplankton species or assemblages upregulate phenolic biosynthesis in response to increased $\mathrm{pCO}_{2}$ is not immediately clear. In contrast to our results, a recent study showed decreased content of these compounds in seagrasses exposed to high $\mathrm{CO}_{2} /$ low $\mathrm{pH}$ condition near a natural $\mathrm{CO}_{2}$ vent $^{14}$. OA has been shown to significantly alter fatty acid content and composition in diatoms ${ }^{6}$. The increased cellular phenolic compounds (shown in this work, Fig. 2a,c), also linked to fatty acid metabolism via $\beta$-oxidation, would further decrease the nutritional value of these organisms. Since phenolic compounds are highly toxic and are found in marine systems ${ }^{15,16}$, an increase in their content in primary producers would undoubtedly lead to significant consequences for food webs and carbon cycles. In addition, as phenolics are known to possess antimicrobial properties ${ }^{17}$, biogeochemical cycles in the oceans may be affected as well.

The present work demonstrated that accumulation of phenolic compounds increased in phytoplankton under $\mathrm{OA}$ and that they were transferred to higher trophic levels (zooplankton). Consequently, accumulation of phenolic compounds in seafood could be a factor that affects the quality of seafood ${ }^{18}$ when the organisms are exposed to OA, which was recently shown to affect the taste of shrimps ${ }^{19}$. Different taxa are known to show differential sensitivities to $\mathrm{OA}^{20}$, which can be altered or amplified under other forcing from ocean changes, such as warming 21 and ultraviolet-B irradiance ${ }^{22}$. At the same time, phytoplankton species can exhibit evolutionary responses to $\mathrm{OA}^{23}$, and the changes in the profile of phenolic compounds remain unknown for long-term adaptation to OA. While altered biochemistry of the diatom Thalassiosira pseudonana grown under OA conditions can decrease egg production of a copepod ${ }^{6}$, exposure to phenol can also decrease egg, faecal pellet production and survival in copepods $^{24,25}$ and toxic compounds can be transferred to higher trophic levels (this work). Therefore, an increase in the content of phenolic compounds in plankton could have far-reaching impacts on seafood qualitative and quantitative values and on species interactions as well as community structures, with consequences for ecosystem functioning and fishery industries.

\section{Methods}

Species and laboratory cultures. E. huxleyi (CCMP 1516), acquired from the Provasoli-Guillard National Center for Culture of Marine Phytoplankton (CCMP), was grown semi-continuously in high (HC, $1,000 \mu \mathrm{atm}, \mathrm{pH}_{\mathrm{NBS}} 7.81$ ) or low (LC,
$395 \mu$ atm, $\mathrm{pH}_{\mathrm{NBS}}$ 8.16) $\mathrm{pCO}_{2}$ (with the $\mathrm{HC}$ representing $\mathrm{CO}_{2}$ levels projected for the end of this century ${ }^{26}$ ) pre-equilibrated artificial seawater enriched with Aquil culture medium. The HC and LC cultures (triplicate independent cultures for each treatment) were maintained in exponential growth phase by continual dilution (every $24 \mathrm{~h}$ ) for 20 generations before being used in the experiments, and the seawater carbonate system parameters were maintained at stable levels (daily variation in $\mathrm{pH}_{\mathrm{NBS}}<0.06$, seawater carbonate system parameters see Supplementary Note 1 and Supplementary Table 3 ) by using freshly prepared medium equilibrated with the target $\mathrm{CO}_{2}$ levels and by sustaining cell concentration within a range of 2.0-4.5 $\times 10^{4}$ cells per ml. The target $\mathrm{CO}_{2}$ levels of $\mathrm{HC}$ and LC medium were achieved by using a $\mathrm{CO}_{2}$ Enrichlor (CE-100B, Wuhan Ruihua Instrument \& Equipment Ltd, China) and bubbling with ambient air, respectively. The cells were grown under a photon flux density of $100 \mu \mathrm{mol}$ photons per $\mathrm{m}^{2} \mathrm{~s}^{-1}$ (12:12 light: dark cycle) in a plant growth chamber (GXZ, Ruihua, Wuhan, China) at $20^{\circ} \mathrm{C}$.

Proteomics analysis. After acclimation for 20 generations, HC- and LC-grown E. huxleyi cells were collected for protein extractions, and then analysed for proteomics by applying a two-dimensional electrophoresis (2-DE) gel and MALDI-TOF-TOF mass spectrometry (MS) approach ${ }^{27}$ to identify the differentially expressed proteins between HC and LC treatments.

Specifically, after the acclimation of E. huxleyi cultures at the relevant treatments for 20 generations, $3 \mathrm{~L}$ samples were collected onto PC filters (Millipore, pore size $0.4 \mu \mathrm{m}$ ), re-suspended in pre-prepared medium equilibrated with the target $\mathrm{CO}_{2}$ level $\left(\mathrm{pH}_{\mathrm{NBS}} 7.81\right.$ and 8.16 for the HC- and LC-grown cells, respectively) and then re-collected by centrifugation at $10,000 \times g$ for $30 \mathrm{~min}$ at $4^{\circ} \mathrm{C}$ for protein extraction. The cell pellets were rinsed twice with precooled sterilized seawater to avoid any carry-over of culture medium and external proteins. Trizol reagent $(1 \mathrm{ml})$ was added to the cell pellet followed by sonication (a total of $2 \mathrm{~min}$ with short pulses of 3-5 s) on ice. Cell lysis was confirmed using light microscopy. Subsequently, $200 \mu \mathrm{l}$ of chloroform was added to the cell lysate before shaking vigorously for $15 \mathrm{~s}$. The mixture was allowed to stand for $5 \mathrm{~min}$ at room temperature before being centrifuged at $12,000 \times g$ for $15 \mathrm{~min}$ at $4{ }^{\circ} \mathrm{C}$. The top pale yellow or colourless layer was removed, and then $300 \mu \mathrm{l}$ of ethanol was added to re-suspend the reddish bottom layer, and the mixture centrifuged at $2,000 \times g$ for $5 \mathrm{~min}$ at $4^{\circ} \mathrm{C}$. The supernatant was then transferred to a new tube, and $2 \mathrm{ml}$ of isopropanol was added. The mixture was allowed to stand for at least $1 \mathrm{~h}$ for precipitation of proteins at $-20^{\circ} \mathrm{C}$. It was then centrifuged at $14,000 \times g$ for $30 \mathrm{~min}$ at $4{ }^{\circ} \mathrm{C}$. Subsequently, the pellet was washed with $95 \%$ ethanol before being air-dried. To solubilize the protein pellet, $30 \mu \mathrm{l}$ of rehydration buffer $(7 \mathrm{M}$ urea, $2 \mathrm{M}$ thiourea, $4 \% \mathrm{w} / \mathrm{v} 3-[(3-$ cholamidopropyl) dimethyl-ammonio]-1-propanesulfonate (CHAPS), $1 \%$ dithiothreitol (DTT) and $0.5 \% \mathrm{v} / \mathrm{v}$ immobilized $\mathrm{pH}$ gradient (IPG)) were added. The resulting solution was centrifuged at $20,000 \times g$ for $30 \mathrm{~min}$ at $4{ }^{\circ} \mathrm{C}$ and the supernatant was collected for 2-DE analysis. The protein content was quantified using a 2-D Quant kit (GE Healthcare, San Francisco, USA).

Exactly $100 \mu \mathrm{g}$ of protein sample (duplicates for each $\mathrm{CO}_{2}$ treatment) was mixed with a rehydration buffer (7 M urea, $2 \mathrm{M}$ thiourea, $4 \%$ w/v 3-[(3cholamidopropyl) dimethyl-ammonio]-1-propanesulfonate, $1 \%$ DTT, and $0.5 \% \mathrm{v} / \mathrm{v}$ IPG) before being loaded onto IPG strips with a linear $\mathrm{pH}$ gradient of 4-7 (Immobiline Drystrip, pH 4-7, GE Healthcare Life Science, Piscataway, USA). The sample was subjected to isoelectric focusing using an IPGphor III system with $24 \mathrm{~cm}$ IPG strips in the following manner: $6 \mathrm{~h}$ at $40 \mathrm{~V}$ (active rehydration), $6 \mathrm{~h}$ at $100 \mathrm{~V} ; 0.5 \mathrm{~h}$ at $500 \mathrm{~V} ; 1 \mathrm{~h}$ at $1,000 \mathrm{~V} ; 1 \mathrm{~h}$ at $2,000 \mathrm{~V} ; 1.5 \mathrm{~h}$ at $10,000 \mathrm{~V}$; and $60,000 \mathrm{Vh}$ at $10,000 \mathrm{~V}$. The minimal Vh applied was at least 60,000 units. Subsequently, the immobilized $\mathrm{pH}$ gradient strips were equilibrated for $15 \mathrm{~min}$ in $10 \mathrm{ml}$ of equilibration buffer containing $6 \mathrm{M}$ urea, $2 \%$ SDS, $50 \mathrm{mM}$ Tris- $\mathrm{Cl}$ (pH 8.8), $30 \%$ glycerol and $1 \%$ DTT, followed by equilibration for $15 \mathrm{~min}$ in alkylation buffer containing $6 \mathrm{M}$ urea, $2 \%$ SDS, $50 \mathrm{mM}$ Tris- $\mathrm{Cl}$ (pH 8.8), $30 \%$ glycerol and $2.5 \%$ iodoacetamide. Two-dimensional SDS-PAGE (2-DE) gels (12.5\%) were run in an EttanDalt system (GE Healthcare) at $1 \mathrm{w}$ per gel for $30 \mathrm{~min}$ and then at $15 \mathrm{w}$ per gel for $6 \mathrm{~h}$. The 2-DE gels were visualized using Coomassie Blue staining and digitized using a gel documentation system on a GS-670 Imaging Densitometer from BioRad (USA) with 2-DE electrophoretogram-matching software. Image analysis was performed using DeCyder version 7.0 software (GE Healthcare) following the manufacturer's instructions.

MS analyses were conducted using an AB SCIEX MALDI TOF-TOF 5800 Analyser (AB SCIEX, Shanghai, China) equipped with a neodymium: yttriumaluminum-garnet laser (laser wavelength was $349 \mathrm{~nm}$ ), in reflection positive-ion mode. Protein identification was conducted according to the previously described method $^{27}$. Briefly, the MS and MS/MS spectra of each protein spot obtained from MALDI-TOF-TOF MS were searched against the NCBI non-redundant protein database using the BLASTX algorithm. If the total ion score confidence interval was above $95 \%$ and the $E$ value was below $\mathrm{e}^{-20}$ at the amino acid sequence level, the sequence similarities were considered to be significant. The details of NCBI ID number, theoretical pI value, theoretical molecular weight, protein score, protein score confidence interval \%, as well as the average relative change are listed in Supplementary Table 1.

Microcosm test. Microcosms of $30 \mathrm{~L}$ (water-jacketed for temperature control) were run from December 2014 to January 2015 at Wuyuan Bay (Xiamen, China) 
on the mesocosm facility platform $\left(24.52^{\circ} \mathrm{N}, 117.18^{\circ} \mathrm{N}\right.$. Surface seawater $(0-1 \mathrm{~m})$ was collected at midday, filtered $(200 \mu \mathrm{m})$ to remove large grazers and dispensed into the microcosms (triplicate microcosms were run for each $\mathrm{CO}_{2}$ treatment). The microcosms were made of polymethyl methacrylate, which allowed $91 \%$ photosynthetically active radiation, $63 \%$ ultraviolet- $\mathrm{A}(315-400 \mathrm{~nm})$ and $6 \%$ ultraviolet-B $(280-315 \mathrm{~nm})$ transmissions under the incident solar radiation. The temperature within the microcosms was controlled to the sea surface temperature (13.0$15.0^{\circ} \mathrm{C}$ ) by circulating in situ seawater through the jacket. The seawater carbonate system in the microcosms was maintained stable by aerating with air of high (HC, $1,000 \mu \mathrm{atm}$ ) or low (LC, $395 \mu \mathrm{atm}) \mathrm{pCO}_{2}$ (see $\mathrm{CO}_{2}$ manipulation method in ref. ${ }^{9}$ ). Samples of $100 \mathrm{ml}$ from each microcosm were collected for the determination of phenolic compounds on day 5 , while the microcosms were exposed to solar irradiance and run until the end of exponential growth phase of the phytoplankton growth (9 days).

Mesocosm test. The Facility for Ocean Acidification Impacts Study of XMU consists of eight independently operated mesocosm units, located at $24.52^{\circ} \mathrm{N}$, $117.18^{\circ} \mathrm{N}$, Wuyuan Bay (Xiamen, China), of which three HC (HC, $1,000 \mu$ atm $\mathrm{CO}_{2}$ ) and three LC (LC, $395 \mu \mathrm{atm} \mathrm{CO}_{2}$ ) units were randomly chosen (for details see in Supplementary Note 2). Four species of phytoplankton, Phaeodactylum tricornutum (CCMA 106), T. weissflogii (CCMP 1335), E. huxleyi (CS-369) and Gephyrocapsa oceanica (NIES-1318) (details about the species are given in Supplementary Note 2) were then inoculated into each mesocosm at equivalent chlorophyll $a$ concentrations to give a total final concentration of 50 cells per $\mathrm{L}$ on 15 June 2013 (day 0). The $\mathrm{pCO}_{2}$ in the mesocosms was controlled by bubbling air of high ( $\mathrm{HC}, 1,000 \mu \mathrm{atm}$ ) or low (LC, $395 \mu \mathrm{atm}) \mathrm{pCO}_{2}$ (details for $\mathrm{pCO}_{2}$ manipulation are provided in the Supplementary Note 2).

Estimation of phenolic compounds. Phenolic content was determined according to ref. 28. Briefly, the cell pellets of phytoplankton or $\sim 300$ zooplankton individuals were placed in $2.5 \mathrm{ml}$ of $95 \%$ ethanol for a period of $48 \mathrm{~h}$ at $47^{\circ} \mathrm{C}$. The cells were sonicated and the supernatant was separated by centrifugation $(4,500 \times g)$ for $10 \mathrm{~min}, 1.0 \mathrm{ml}$ of which was transferred to glass test tubes along with $1.0 \mathrm{ml} 95 \%$ ethanol, $5.0 \mathrm{ml}$ distilled water and $0.5 \mathrm{ml}$ of $50 \%$ Folin-Ciocalteu reagent (Sigma Chemical, USA). The solution was allowed to react for $5 \mathrm{~min}$, then $1.0 \mathrm{ml}$ of $5 \% \mathrm{Na}_{2} \mathrm{CO}_{3}$ was added, and the mixture was vortexed and placed in the darkness for $1 \mathrm{~h}$. Absorbance was determined with a scanning spectrophotometer (DU800, Beckman, Fullerton, CA, USA) at $725 \mathrm{~nm}$ and plotted against a standard curve obtained from gallic acid.

Measurement of respiration. Mitochondrial respiration rates of laboratory cultures were determined by a Clark-type oxygen electrode in darkness. The respiratory carbon loss in phytoplankton assemblages from the mesocosms over $12 \mathrm{~h}$ was calculated as the difference in the amount of fixed carbon, using ${ }^{14} \mathrm{C}$ tracer methods, between the two time spans (carbon fixation $12 \mathrm{~h}$-carbon fixation $24 \mathrm{~h}$; for details, see the Supplementary Note 3).

Feeding experiments. Zooplankton individuals were obtained at night through horizontal hauling with a medium plankton net (mesh diameter, $112 \mu \mathrm{m}$ ) from surface water in Wuyuan Bay. Collected zooplankton samples were nursed in culture dishes $(400 \mathrm{ml})$ in in situ seawater pre-equilibrated with target high $(1,000 \mu \mathrm{atm})$ or low $\mathrm{pCO}_{2}(395 \mu \mathrm{atm})$ levels for $12 \mathrm{~h}$ before using them. Zooplankton in each culture under $\mathrm{HC}$ or LC treatment (three independent replicates for each $\mathrm{CO}_{2}$ treatment) were fed with either HC- or LC-grown phytoplankton cells collected from the microcosms or mesocosms at about $15 \mu \mathrm{g}$ chlorophyll $a$ per $\mathrm{L}$ every $12 \mathrm{~h}$. The cultures were maintained under solar radiation by covering with five neutral density screens (providing $6 \%$ of incident solar radiation). After the feeding procedure $(24 \mathrm{~h})$, zooplankton samples were collected for measurements of phenolic content and sub-samples were collected for microscopic enumeration.

\section{References}

1. Riebesell, U. \& Tortell, P. D. in Ocean Acidification. (eds Gattuso, J. P. \& Hansson, L.) 99-121 (Oxford Univ. Press, 2011).

2. Beardall, J., Stojkovic, S. \& Gao, K. Interactive effects of nutrient supply and other environmental factors on the sensitivity of marine primary producers to ultraviolet radiation: implications for the impacts of global change. Aquat. Biol. 22, 5-23 (2014).

3. Benner, I. et al. Emiliania huxleyi increases calcification but not expression of calcification-related genes in long-term exposure to elevated temperature and pCO 2 . Philos. Trans. R Soc. Lond. B Biol. Sci. 368, 20130049 (2013).

4. Riebesell, U. \& Gattuso, J.-P. Lessons learned from ocean acidification research. Nat Clim. Chang. 5, 12-14 (2015).

5. Anderca, M. I., Furuichi, T., Pinontoan, R. \& Muto, S. Identification of a mitochondrial nucleoside diphosphate kinase from the green alga Dunaliella tertiolecta. Plant Cell Physiol. 43, 1276 (2002).

6. Rossoll, D. et al. Ocean acidification-induced food quality deterioration constrains trophic transfer. PLoS ONE 7, e34737 (2012).
7. Schoo, K. L., Malzahn, A. M., Krause, E. \& Boersma, M. Increased carbon dioxide availability alters phytoplankton stoichiometry and affects carbon cycling and growth of a marine planktonic herbivore. Mar. Biol. 160, 2145-2155 (2013).

8. Wu, Y., Gao, K. \& Riebesell, U. $\mathrm{CO}_{2}$-induced seawater acidification affects physiological performance of the marine diatom Phaeodactylum tricornutum. Biogeosciences 7, 2915-2923 (2010).

9. Gao, K. et al. Rising $\mathrm{CO}_{2}$ and increased light exposure synergistically reduce marine primary productivity. Nat Clim. Chang. 2, 519-523 (2012).

10. Hennon, G. M., Quay, P., Morales, R. L., Swanson, L. M. \& Virginia Armbrust, E Acclimation conditions modify physiological response of the diatom Thalassiosira pseudonana to elevated $\mathrm{CO}_{2}$ concentrations in a nitrate-limited chemostat. J. Phycol. 50, 243-253 (2014).

11. Taylor, A. R., Chrachri, A., Wheeler, G., Goddard, H. \& Brownlee, C. A voltagegated $\mathrm{H}^{+}$channel underlying $\mathrm{pH}$ homeostasis in calcifying coccolithophores. PLoS Biol. 9, e1001085 (2011).

12. Raven, J. A., Beardall, J. \& Giordano, M. Energy costs of carbon dioxide concentrating mechanisms in aquatic organisms. Photosynth. Res. 121, 111-124 (2014).

13. Xu, J. \& Gao, K. Future $\mathrm{CO}_{2}$-induced ocean acidification mediates the physiological performance of a green tide alga. Plant Physiol. 160, 1762-1769 (2012).

14. Arnold, T. et al. Ocean acidification and the loss of phenolic substances in marine plants. PLoS ONE 7, e35107 (2012).

15. Boyd, T. J. \& Carlucci, A. Degradation rates of substituted phenols by natural populations of marine bacteria. Aquat. Toxicol. 25, 71-82 (1993).

16. Ianora, A. et al. New trends in marine chemical ecology. Estuar. Coast. 29, 531-551 (2006)

17. Arnold, T. M. \& Targett, N. M. Marine tannins: the importance of a mechanistic framework for predicting ecological roles. J. Chem. Ecol. 28, 1919-1934 (2002).

18. Maga, J. A. Simple phenol and phenolic compounds in food flavor. Crit. Rev. Food Sci. Nutr. 10, 323-372 (1978).

19. Dupont, S., Hall, E., Calosi, P. \& Lundve, B. First evidence of altered sensory quality in a shellfish exposed to decreased $\mathrm{pH}$ relevant to Ocean Acidification. J. Shellfish Res. 33, 857-861 (2014).

20. Kroeker, K. J. et al. Impacts of ocean acidification on marine organisms: quantifying sensitivities and interaction with warming. Glob. Chang. Biol. 19, 1884-1896 (2013).

21. Pörtner, H. O. \& Farrell, A. P. Physiology and climate change. Science 322, 690-692 (2008).

22. Gao, K., Helbling, E. W., Häder, D-P. \& Hutchins, D. A. Responses of marine primary producers to interactions between ocean acidification, solar radiation and warming. Mar. Ecol. Prog. Ser. 470, 167-189 (2012).

23. Sunday, J. M. et al. Evolution in an acidifying ocean. Trends Ecol. Evol. 29, 117-125 (2014).

24. Buttino, I. The effect of low concentrations of phenol and ammonia on egg production rates, fecal pellet production and egg viability of the calanoid copepod Acartia clausi. Mar. Biol. 119, 629-634 (1994).

25. Bechmann, R. Effect of the endocrine disrupter nonylphenol on the marine copepod Tisbe battagliai. Sci. Total Environ. 233, 33-46 (1999).

26. IPCC. Climate Change 2013. The Physical Science Basis (eds Stocker, T. F. et al.) (Cambridge Univ. Press, 2013).

27. Wang, D., Gao, Y., Lin, L. \& Hong, H.-S. Comparative proteomic analysis reveals proteins putatively involved in toxin biosynthesis in the marine dinoflagellate Alexandrium catenella. Mar. Drugs 11, 213-232 (2013).

28. Shetty, K., Curtis, O. F., Levin, R. E., Witkowsky, R. \& Ang, W. Prevention of vitrification associated with in vitro shoot culture of oregano (Origanum vulgare) by Pseudomonas spp. J. Plant Physiol. 147, 447-451 (1995).

\section{Acknowledgements}

This study was supported by National Natural Science Foundation (41430967; 41120164007), State Oceanic Administration (GASI-03-01-02-04), Joint project of National Natural Science Foundation of China and Shandong province (No. U1406403), Strategic Priority Research Program of Chinese Academy of Sciences (No. XDA11020302). Visits of S.D. and J.B. to Xiamen University were supported by ' 111 ' project from Ministry of Education and the State Key Laboratory of Marine Environmental Science (MEL). We thank Yaping Wu for his leading roles in microcosm and mesocosm experiments, and X. Lin, X. Liu, L. Guo, Y. Li, W. Li, Y. Li, T. Xing, X. Cai, J. Ding, F. Li, S. Tong, X. Yi, D. Yan, H. Miao, Z. Li, R. Huang, W. Zhao and X. Zeng for their kind assistance in operations of the microcosms and mesocosms. We also thank D. Wang, H. Zhang and Z. Xie for their kind assistance in analysis of the proteomics.

\section{Author contributions}

On the basis of an original idea from P.J. and K.G., the concept of this paper was developed in discussion between all authors. P.J., T.W. and N.L. performed the 
experiments under the supervision of K.G., S.D., J.B., P.W.B. and U.R. contributed to the data analysis and discussion and writing of the paper.

\section{Additional information}

Supplementary Information accompanies this paper at http://www.nature.com/

naturecommunications

Competing financial interests: The authors declare no competing financial interests.

Reprints and permission information is available online at http://npg.nature.com/ reprintsandpermissions/
How to cite this article: Jin, P. et al. Ocean acidification increases the accumulation of toxic phenolic compounds across trophic levels. Nat. Commun. 6:8714 doi: $10.1038 /$ ncomms9714 (2015).

cc (i) This work is licensed under a Creative Commons Attribution 4.0 International License. The images or other third party material In
in this article are included in the article's Creative Commons license, unless indicated otherwise in the credit line; if the material is not included under the Creative Commons license, users will need to obtain permission from the license holder to reproduce the material. To view a copy of this license, visit http://creativecommons.org/ licenses/by/4.0/ 